\title{
Dietary fish protein hydrolysates containing bioactive motifs affect serum and adipose tissue fatty acid compositions, serum lipids, postprandial glucose regulation and growth in obese Zucker fa/fa rats
}

\author{
Aslaug Drotningsvik ${ }^{1}$, Svein A. Mjøs ${ }^{2,3}$, Daniela M. Pampanin ${ }^{4}$, Rasa Slizyte ${ }^{5}$, Ana Carvajal ${ }^{5}$, \\ Tore Remman ${ }^{6}$, Ingmar Høgøy ${ }^{7}$ and Oddrun A. Gudbrandsen ${ }^{1 *}$ \\ ${ }^{1}$ Dietary Protein Research Group, Department of Clinical Medicine, University of Bergen, 5020 Bergen, Norway \\ ${ }^{2}$ Department of Chemistry, University of Bergen, PO Box 7803, 5020 Bergen, Norway \\ ${ }^{3}$ Nofima BioLab, PO Box 1425 Oasen, 5828 Bergen, Norway \\ ${ }^{4}$ International Research Institute of Stavanger, Mekjarvik 12, 4070 Randaberg, Norway \\ ${ }^{5}$ SINTEF Fisheries and Aquaculture, Brattørkaia 17 C, 7465 Trondheim, Norway \\ ${ }^{6}$ Nutrimar AS, Industrivei 23, 7266 Kverva, Norway \\ ${ }^{7}$ Blue Protein, 5393 Storebø, Norway \\ (Submitted 1 July 2016 - Final revision received 22 August 2016 - Accepted 6 September 2016)
}

\section{Abstract}

The world's fisheries and aquaculture industries produce vast amounts of protein-containing by-products that can be enzymatically hydrolysed to smaller peptides and possibly be used as additives to functional foods and nutraceuticals targeted for patients with obesity-related metabolic disorders. To investigate the effects of fish protein hydrolysates on markers of metabolic disorders, obese Zucker fa/fa rats consumed diets with $75 \%$ of protein from casein/whey (CAS) and $25 \%$ from herring (HER) or salmon (SAL) protein hydrolysate from rest raw material, or $100 \%$ protein from CAS for 4 weeks. The fatty acid compositions were similar in the experimental diets, and none of them contained any long-chain $n$ - 3 PUFA. Ratios of lysine:arginine and methionine:glycine were lower in HER and SAL diets when compared with CAS, and taurine was detected only in fish protein hydrolysate diets. Motifs with reported hypocholesterolemic or antidiabetic activities were identified in both fish protein hydrolysates. Rats fed HER diet had lower serum HDL-cholesterol and LDL-cholesterol, and higher serum TAG, MUFA and $n$-3: $n$-6 PUFA ratio compared with CAS-fed rats. SAL rats gained more weight and had better postprandial glucose regulation compared with CAS rats. Serum lipids and fatty acids were only marginally affected by SAL, but adipose tissue contained less total SFA and more total $n$ - 3 PUFA when compared with CAS. To conclude, diets containing hydrolysed rest raw material from herring or salmon proteins may affect growth, lipid metabolism, postprandial glucose regulation and fatty acid composition in serum and adipose tissue in obese Zucker rats.

Key words: Herring: Salmon: Obesity: Cholesterol: Bioactive motifs

The health benefits of fish consumption, especially of fatty fish, have traditionally been attributed to the effect of long-chain $n$-3 PUFA, and although the TAG-lowering effect of fish oil and long-chain $n$-3 PUFA is well documented, there is controversy as to the cholesterol-regulating and glucose-regulating effects of the marine $n-3$ fatty acids ${ }^{(1-9)}$. Studies in rats and humans suggest that also fish proteins, either eaten as fish or purified intact or hydrolysed proteins, may be beneficial to human health and affect risk factors of CVD and type 2 diabetes $^{(10-22)}$. Little is known about how protein hydrolysates containing small peptides from fatty fish, such as herring and salmon, may affect markers of obesity-related disorders.

The total production and utilisation from the world's fisheries and aquaculture was estimated to be 157.9 million tonnes in
2012, with $136 \cdot 2$ million tonnes utilised for human consumption and 21.7 million tonnes utilised for non-food purposes ${ }^{(23)}$, such as fish protein concentrate, fishmeal and oil for the feed market. The global demand for $n-3$ PUFA ingredients in 2010 was estimated to be a staggering US $\$ 1.595$ billion, whereas the market for protein ingredients in the USA alone was estimated to be worth US\$45-60 million ${ }^{(23)}$. Fish remains and other fish by-products such as heads, tails, bones and other cut-offs should be explored to a greater extent as protein sources for human consumption. Dietary proteins have nutritional properties depending on their amino acid content, and in addition these proteins have potential functional properties on the basis of their amino acid sequence. Bioactive motifs can be liberated during digestion (enzymatic hydrolysis), microbial fermentation

Abbreviations: CAS, casein/whey; HER, herring; SAL, salmon; WAT, white adipose tissue.

* Corresponding author: O. A. Gudbrandsen; fax +47 5597 5890; email oddrun.gudbrandsen@k1.uib.no 
or in vitro hydrolysis (processing) of proteins before ingestion. The bioactive peptides are usually 2-20 amino acids in length, and may enter the circulatory system after being absorbed through the intestine or produce local effects in the digestive tract ${ }^{(24)}$. Peptides from fish protein hydrolysates have been shown to have antihypertensive, antioxidative, antiproliferative, anticoagulant and calcium-binding abilities ${ }^{(24,25)}$, and we have recently identified small bioactive motifs with hypocholesterolemic, antidiabetic, antioxidant opioid agonist/antagonist activities in rest raw materials from Atlantic herring ${ }^{(26)}$, Atlantic salmon and Atlantic $\operatorname{cod}^{(27)}$. Hydrolysed proteins from fish should be of great interest for the food industry as additives to functional foods and as nutraceuticals, and good documentation of the health benefits of fish hydrolysates may contribute to a more sustainable fishery and a healthier population.

In the present study, we investigated the effects of two in vitro enzymatically hydrolysed fish proteins as part of normoenergetic diets fed to obese Zucker fa/fa rats. Rest raw materials from herring and salmon were chosen as protein sources, as the industrial processing of these fish types produces vast amounts of rest raw materials that we believe should be commercially exploited for human consumption. Both hydrolysates were examined for known bioactive motifs with hypocholesterolemic and/or antidiabetic effects. The obese Zucker fa/fa rat has an abnormal lipid metabolism and presents changes often seen in human obesity, and is the most used and most representative rat model for studies of metabolic complications and possible treatments of obesity ${ }^{(28)}$. Visible obesity is present already 3-5 weeks after birth, and in addition the obese Zucker rats develop a range of endocrinological abnormalities resembling human metabolic syndrome, including insulin resistance, dyslipidaemia, mild glucose intolerance and hyperinsulinaemia(28). The aim of the present study was to see whether herring and salmon protein hydrolysates containing peptides mainly $<4000 \mathrm{~g} / \mathrm{mol}$ would affect typical markers for metabolic disorders in a rat model for obesity and diabetes.

\section{Methods}

\section{Animals and diets}

In total, eighteen male Zucker fa/fa rats (HsdOla:Zucker-Lepr, from Harlan Laboratories) were assigned to three experimental groups of six rats each with comparable mean body weight. The rats were housed in pairs in Makrolon IV cages (EHRET $\mathrm{GmbH} \& \mathrm{Co}$.) in a room maintained in a $12 \mathrm{~h}$ light $-12 \mathrm{~h}$ dark cycle (light from 07.00 to 19.00 hours) with constant temperature of $20 \pm 3^{\circ} \mathrm{C}$ and relative humidity of $65 \pm 15 \%$. The rats were acclimatised under these conditions before the start of the experiment.

The intervention period started when the rats weighed 350 (sD 20) g. The rats were fed modified, semi-purified experimental diets on the basis of $\mathrm{AIN}-93 \mathrm{G}^{(29)}$ (Table 1) for 4 weeks. The casein/whey-(CAS) based diet contained $20 \mathrm{wt} \%$ proteins from casein/whey (90\% casein, $10 \%$ whey) from KAPA JP (Armor Protéines). The herring (HER) diet contained $15 \mathrm{wt} \%$ proteins from casein/whey and $5 \mathrm{wt} \%$ proteins from herring protein hydrolysate, and the SAL diet contained $15 \mathrm{wt} \%$ proteins
Table 1. Composition of the of the experimental diets ( $\mathrm{g} / \mathrm{kg}$ diet)

\begin{tabular}{lccc}
\hline & CAS & HER & SAL \\
\hline Casein protein* & 222.22 & 170.45 & 170.45 \\
Herring protein hydrolysate† & & 113.60 & \\
Salmon protein hydrolysate & & & 113.60 \\
Maize starch & 505.61 & 443.74 & 443.74 \\
Sucrose & 90.00 & 90.00 & 90.00 \\
Cellulose & 50.00 & 50.00 & 50.00 \\
Soyabean Oil & 70.00 & 70.00 & 70.00 \\
Tert-butylhydroquinone & 0.014 & 0.014 & 0.014 \\
Mineral mix (AIN-93-MX) & 35.00 & 35.00 & 35.00 \\
Vitamin mix (AIN-93-VX) & 10.00 & 10.00 & 10.00 \\
L-Met & 1.60 & 1.60 & 1.60 \\
L-Cystine & 3.00 & 3.00 & 3.00 \\
Choline bitartrate§ & 2.50 & 2.50 & 2.50 \\
Growth and maintenance supplementll & 10.00 & 10.00 & 10.00 \\
\hline
\end{tabular}

CAS, casein/whey; HER, herring; SAL, salmon.

* Contains $90 \%$ crude protein.

† Contains $44 \%$ crude protein, $15 \%$ maltodextrin, $36 \%$ ash, $3 \%$ moisture.

† Contains $44 \%$ crude protein, $15 \%$ maltodextrin, $31 \%$ ash, $5 \%$ moisture.

$\S$ Contains $41 \%$ choline.

॥ Contains $2.5 \mathrm{~g}$ vitamin $\mathrm{B}_{12}, 2.5 \mathrm{~g}$ vitamin $\mathrm{K}_{1}$ and $995 \mathrm{~g}$ sucrose per $\mathrm{kg}$.

from casein/whey and $5 \mathrm{wt} \%$ proteins from salmon protein hydrolysate. The casein/whey was not hydrolysed before use. All other ingredients were purchased from Dyets Inc. The diets were prepared according to the instructions for the AIN-93G ${ }^{(29)}$, with addition of $1 \mathrm{wt} \%$ growth and maintenance supplement as recommended by Dyets Inc. All rats had free access to tap water and feed (ad libitum). The feed was contained in ceramic bowls that were too heavy for the rats to knock over. Feed leftovers were thrown away and newly thawed feed was provided every day except Sundays (double doses provided on Saturdays). As the feed was given as a powder formula, the rats always had access to wood chewing sticks. The rats were weighed weekly during the intervention period.

The rats were housed in Makrolon IV cages with grids for $24 \mathrm{~h}$ on day 18 of the intervention period, without fasting in advance, for collection of faeces and measurements of feed intake.

A meal tolerance test was performed using a standardised meal on day 22 of the intervention period. The glucose load was prepared as a modified, semi-purified meal on the basis of AIN-93G ${ }^{(29)}$ with $400 \mathrm{~g}$ of sucrose/ $\mathrm{kg}$ feed (composition of feed for meal tolerance test: $225 \mathrm{~g}$ casein ( $88 \%$ raw protein; Armor Protéines), $70 \mathrm{~g}$ of soyabean oil, $390 \mathrm{~g}$ of sucrose, $203 \mathrm{~g}$ of maize starch, $50 \mathrm{~g}$ of cellulose, $35 \mathrm{~g}$ of mineral mix, $10 \mathrm{~g}$ of vitamin mix, $3 \mathrm{~g}$ of L-cystine, $1.6 \mathrm{~g}$ of $\mathrm{L}$-methionine, $2.5 \mathrm{~g}$ of choline bitartrate and $10 \mathrm{~g}$ of growth and maintenance supplement; all ingredients except casein were purchased from Dyets Inc.). The rats were housed individually and under fasting conditions from 20.00 to 08.00 hours, before they received a meal corresponding to $2 \mathrm{~g}$ of sucrose/ $\mathrm{kg}$ body weight. All rats were fed the same diet for the meal tolerance test. Body weight was measured before the meal load was calculated. The rats were allowed a maximum of $15 \mathrm{~min}$ to finish the meal. The dorsal tail vein was punctuated and blood glucose was measured using a blood glucose measuring device (Contour; Bayer Consumer Care AG). Blood glucose was measured in the fasting condition and 60, 120 and $180 \mathrm{~min}$ after the rats had finished eating the meal. 
The rats were euthanised while under anaesthesia with 2-4\% isoflurane (Isoba vet; Intervet, Schering-Plough Animal Health) mixed with nitrous oxide and oxygen after 4 -week intervention, after a 12-h fast with free access to tap water. The body length of the rats was measured with a ruler when rats were anaesthetised. Blood was drawn directly from the heart and collected in Vacuette Z Serum Clot Activator Tubes (Greiner Bio-One) for isolation of serum. Liver, skeletal muscle from the thigh and epididymal white adipose tissue (WAT) were dissected out and weighed. Serum and tissues were frozen in liquid $\mathrm{N}_{2}$ and stored at $-80^{\circ} \mathrm{C}$ until analysis.

\section{Ethics approval}

The animal experiment was approved in accordance with the Norwegian regulation on animal experimentation (approval no. 2012-4610). The protocol was approved by the Norwegian State Board of Biological Experiments with Living Animals. The animal care and use programme at the Faculty of Medicine and Dentistry at University of Bergen is accredited by the Association for Assessment and Accreditation of Laboratory Animal Care International.

\section{Preparation of fish protein hydrolysates}

Protein hydrolysates from fresh Norwegian spring spawning herring by-products (Grøntvedt Pelagic AS) and fresh backbones after filleting of salmon (SalMar ASA) were prepared by the same methods. First, the fish remains were minced and heated to $55^{\circ} \mathrm{C}$ before they were mixed with warm water (1:1). Enzymatic hydrolysis was started by adding $0 \cdot 1 \%$ (dry weight of enzymes per weight wet material) of a mixture of papain and bromelain $(1: 1, \mathrm{w} / \mathrm{w})$ (both powder on maltodextrin; Enzybel International S.A), by SINTEF Fisheries and Aquaculture. After $1 \mathrm{~h}$ of hydrolysis, the hydrolysis mixture was heated to above $90^{\circ} \mathrm{C}$ to ensure inactivation of enzymes. Thereafter, heated material was pumped to a Tricanter centrifuge (Flottweg Separation Technology) where oil, hydrolysate and sediments were separated. The hydrolysate was preserved by adding acetic acid to $\mathrm{pH}<4 \cdot 0$. Next, the dissolved hydrolysates were heated to $73^{\circ} \mathrm{C}$ and filtered through a ceramic membrane filter $(50 \mathrm{~nm}$, Pall Membralox; Pall Corporation), and $\mathrm{NaOH}$ was added until a $\mathrm{pH}$ of 8.5 was obtained and until precipitation was observed (Nofima BioLab). The precipitate was removed and the $\mathrm{pH}$ of the hydrolysate solutions were adjusted to 6.5 using $\mathrm{HCl}$. The solutions were dried in a vacuum evaporator to achieve a DM content of $40 \%$, and then $15 \%$ maltodextrin (by DM weight) was added before drying the hydrolysates in a spray dryer.

\section{Analyses of protein hydrolysates and diets}

The contents of amino acids, ash and moisture and the distributions of peptides on the basis of molecular weights in the fish hydrolysates, as well as the amino acid composition and total energy content in the diets, were analysed by Nofima BioLab. Peptide size distributions were measured by combining results from HPLC size exclusion chromatography using a Superdex ${ }^{\mathrm{TM}}$ Peptide 10/300 GL column (measuring range
200-20000 g/mol; GE Healthcare) and a TSKgel G2000SW column (measuring range $2000-70000 \mathrm{~g} / \mathrm{mol}$; Tosoh), both equipped with UV detectors ${ }^{(30)}$. The fatty acid composition in the diets was analysed by GC, as previously described ${ }^{(21,31-34)}$. Identification of bioactive motifs in the water-soluble herring and salmon hydrolysates was performed by the International Research Institute of Stavanger (IRIS), as described by Pampanin et $a l .{ }^{(26)}$, using LC-MS/MS Orbitrap analyses. Raw data from the Orbitrap were analysed using the Proteome Discoverer 1.3 (Thermo Scientific) with the Sequest algorithm to search against peptide sequences that has been reported by others to have hypocholesterolaemic and/or antidiabetic effects. The herring and salmon protein hydrolysates were examined for the presence of the following motifs: $\operatorname{ALPMH}^{(35)}, \mathrm{GLDIQK}^{(35)}$,

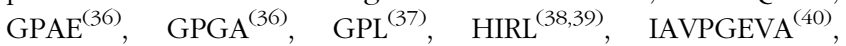
IIAEK $^{(35)}$, IPI $^{(41)}, \operatorname{LPGP}^{(42)}, \operatorname{LPYPR}^{(39)}, \mathrm{PGPL}^{(42,43)}, \mathrm{RPLKPW}^{(44)}$,

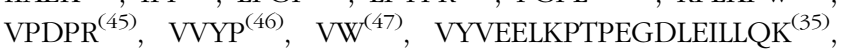
$\mathrm{YPFVV}^{(48)}$ and YYPL ${ }^{(47)}$.

\section{Analyses in fasting serum}

Fasting serum concentrations of total cholesterol, LDL-cholesterol, HDL-cholesterol, TAG, total bile acids and alanine transaminase were analysed by accredited methods at the Laboratory of Clinical Biochemistry at Haukeland University Hospital. Serum NEFA and free cholesterol were analysed on the Cobas c 111 system (Roche Diagnostics $\mathrm{GmbH}$ ) using the NEFA FS kit (DiaSys, Diagnostic Systems GmbH) and the free cholesterol FS kit (DiaSys), respectively. Serum cholesteryl ester was calculated as the difference between total and free cholesterol. The EIA-2048 kit (DRG Instruments GmbH) was used for analyses of serum insulin.

\section{Analyses of lipids in liver, muscle and faeces}

Lipids were extracted from liver, skeletal muscle and faeces by the method of Bligh \& Dyer ${ }^{(31)}$, and analysed as previously described $^{(21)}$.

\section{Total faecal bile acids}

Faecal total bile acids ( $3 \alpha$-hydroxy bile acids) were measured in freeze-dried faeces ${ }^{(49)}$, and analysed as previously described ${ }^{(21)}$.

\section{Fatty acids in serum, liver, muscle and adipose tissue}

Lipids were extracted from liver and skeletal muscle using a mixture of chloroform and methanol ${ }^{(31)}$ before methylation. Serum and adipose tissue samples were methylated without prior extraction of lipids. Extracts, serum and adipose tissue were methylated and analysed as described previously ${ }^{(21,32-34)}$.

\section{Statistical analysis}

The data were evaluated by one-way ANOVA with Dunnett post hoc test for multiple comparisons when appropriate, and the cut-off level for statistical significance was taken at a probability of 0.05. Rats fed a CAS diet served as controls. Data are presented as mean values and standard deviation for six rats in each group. 


\section{Results}

\section{Diets}

The dietary contents of most indispensable amino acids were comparable between the diets, but the contents of arginine, glycine and taurine were higher and the ratios of lysine:arginine and of methionine:glycine were lower in HER and SAL diets when compared with the CAS diet (Table 2). The contents of fatty acids were only marginally different between the diets (Table 2). We found no traces of long-chain n-3 PUFA (20:5n-3, 22:5n-3 and $22: 6 n-3)$ in any of the diets. The herring and salmon protein hydrolysates contained peptides mainly $<4000 \mathrm{~g} / \mathrm{mol}$ (constituting 96.7 and $92.7 \%$ of total peptides, respectively). The distribution of peptides of size $200-500 \mathrm{~g} / \mathrm{mol}$

Table 2. Contents of indispensable amino acids, the functional amino acid glycine, the conditionally essential arginine, taurine, the ratios of lysine:arginine and methionine:glycine, and contents of fatty acids* in the diets

\begin{tabular}{|c|c|c|c|}
\hline Diet $(\mathrm{g} / \mathrm{kg})$ & CAS & HER & SAL \\
\hline \multicolumn{4}{|l|}{ Amino acids } \\
\hline Arg† & $7 \cdot 7$ & 11.5 & $9 \cdot 0$ \\
\hline Gly & $4 \cdot 0$ & $7 \cdot 4$ & 8.7 \\
\hline His & $5 \cdot 8$ & $5 \cdot 6$ & $5 \cdot 8$ \\
\hline Ile & 11.5 & $10 \cdot 2$ & 10.5 \\
\hline Leu & $20 \cdot 6$ & $18 \cdot 6$ & 18.7 \\
\hline Lys & $18 \cdot 5$ & $17 \cdot 9$ & $17 \cdot 7$ \\
\hline Met & $7 \cdot 6$ & $7 \cdot 3$ & 7.5 \\
\hline Phe & $10 \cdot 6$ & $9 \cdot 4$ & $9 \cdot 6$ \\
\hline Thr & $11 \cdot 2$ & $10 \cdot 9$ & $10 \cdot 7$ \\
\hline Val & $13 \cdot 8$ & $12 \cdot 7$ & $12 \cdot 7$ \\
\hline Tau & ND & $1 \cdot 2$ & 0.4 \\
\hline Lys:Arg ratio & $2 \cdot 4$ & 1.6 & $2 \cdot 0$ \\
\hline Met:Gly ratio & 1.9 & 1.0 & 0.9 \\
\hline \multicolumn{4}{|l|}{ Fatty acids } \\
\hline $16: 0$ & $7 \cdot 42$ & $7 \cdot 34$ & $7 \cdot 34$ \\
\hline $18: 0$ & $2 \cdot 50$ & 2.48 & $2 \cdot 48$ \\
\hline $18: 1 n-9$ & $13 \cdot 86$ & $13 \cdot 88$ & 13.85 \\
\hline $18: 1 n-7$ & 0.92 & 0.92 & 0.92 \\
\hline $18: 2 n-6$ & 35.57 & $35 \cdot 70$ & 35.71 \\
\hline $18: 3 n-3$ & $5 \cdot 10$ & $5 \cdot 11$ & $5 \cdot 13$ \\
\hline
\end{tabular}

CAS, casein/whey; HER, herring; SAL, salmon.

* Only fatty acids found in levels $>0.5 \mathrm{~g} / \mathrm{kg}$ diet are shown. Long-chain $n-3$ PUFA $(20: 5 n-3,22: 5 n-3,22: 6 n-3)$ were not detected in any of the diets.

$\dagger$ Arginine can be synthesised by the rat, but not in sufficient amounts to meet the demands for normal growth ${ }^{(50)}$. was similar between the two protein hydrolysates (herring, $14.3 \%$; salmon, $14.0 \%$ ), strongly indicating that the amounts of dipeptides and tripeptides were similar in the HER and SAL diets. In addition, the contents of peptides in the range 200-1000 g/mol, comprising peptides with approximately 2-5 amino acids, were comparable in herring and salmon hydrolysates ( 31.9 and $31.2 \%$, respectively). The fraction of peptides $<200 \mathrm{~g} / \mathrm{mol}$, comprising free amino acids and miscellaneous water-soluble components absorbing light with wavelength of $214 \mathrm{~nm}$, was larger in herring hydrolysate compared with salmon hydrolysate (34.2 and $20.3 \%$, respectively). Peptides/ motifs with hypocholesterolemic and/or antidiabetic activities were found in both fish hydrolysates. Antidiabetic motifs GPL, IPI and VW were found in both herring and salmon hydrolysates, whereas antidiabetic motifs GPAE and LGPG were found only in herring hydrolysate. The hypocholesterolemic and antidiabetic motif PGPL was also found in both fish hydrolysates. Sequence IIAEK, a powerful hypocholesterolemic peptide, was found only in herring hydrolysate.

\section{Energy intake and growth}

The body weights in the fish hydrolysate groups were similar to that of the CAS group at baseline (Table 3). The mean body weight:square body length (without tail) ratio at euthanasia and mean weights of liver, thigh muscle and epididymal WAT relative to body weight were similar in fish hydrolysate groups and CAS. The energy intake (relative to body weight) and the faecal output of DM relative to body weight were similar in fish hydrolysate groups and CAS.

The mean percentage growth during the study period was significantly higher in the SAL group when compared with the CAS group $(P=0.035)$, and this was statistically significant after 2 weeks $(P=0.049)$ and tended to be significant after 3 weeks ( $P=0.063$ ) of intervention (Fig. 1). The mean growth in the HER group was similar to that of CAS.

\section{Meal tolerance test}

Fasting glucose concentrations were similar in CAS and fish hydrolysate groups (CAS, $5 \cdot 0$ (sD 0.9); HER, 4.7 (sD 0.2); SAL, 5.0 $(\mathrm{SD} 0.5) \mathrm{mmol} / \mathrm{l})$. The glucose concentration increased in all rats

Table 3. Body weight at baseline, relative organ weight at time of euthanasia, and daily energy intake and faecal DM at day 18 (Mean values and standard deviations, $n 6$ rats in each group)

\begin{tabular}{|c|c|c|c|c|c|c|}
\hline & \multicolumn{2}{|c|}{ CAS } & \multicolumn{2}{|c|}{ HER } & \multicolumn{2}{|c|}{ SAL } \\
\hline & Mean & SD & Mean & SD & Mean & SD \\
\hline Body weight at baseline $(\mathrm{g})$ & 344 & 18 & 356 & 15 & 349 & 24 \\
\hline Body weight gain $(\mathrm{g})$ & 127 & 17 & 138 & 20 & $155^{\star}$ & 12 \\
\hline Body weight:square body length without tail ratio $\left(\mathrm{kg} / \mathrm{m}^{2}\right)$ & 8.8 & 0.4 & 8.6 & 0.7 & 8.9 & 0.3 \\
\hline Liver ( $\mathrm{g} / \mathrm{kg}$ body weight) & $32 \cdot 6$ & $1 \cdot 6$ & 31.9 & 1.6 & $32 \cdot 8$ & 3.5 \\
\hline Thigh skeletal muscle (g/kg body weight) & 3.23 & 0.29 & $3 \cdot 23$ & 0.18 & 3.33 & 0.39 \\
\hline Epididymal white adipose tissue ( $\mathrm{g} / \mathrm{kg}$ body weight) & 24.0 & $1 \cdot 1$ & 24.4 & 1.9 & $22 \cdot 6$ & $2 \cdot 2$ \\
\hline Energy intake ( $\mathrm{kJ} / \mathrm{kg}$ body weight) & 1280 & 74 & 1331 & 131 & 1361 & 106 \\
\hline Faecal output (g dry weight/kg body weight) & $6 \cdot 1$ & 0.5 & $7 \cdot 3$ & 1.3 & 7.5 & 1.9 \\
\hline
\end{tabular}

CAS, casein/whey; HER, herring; SAL, salmon.

* Mean value was significantly different from that of the CAS group $(P<0.05$; evaluated by one-way ANOVA with Dunnett's post hoc test). 


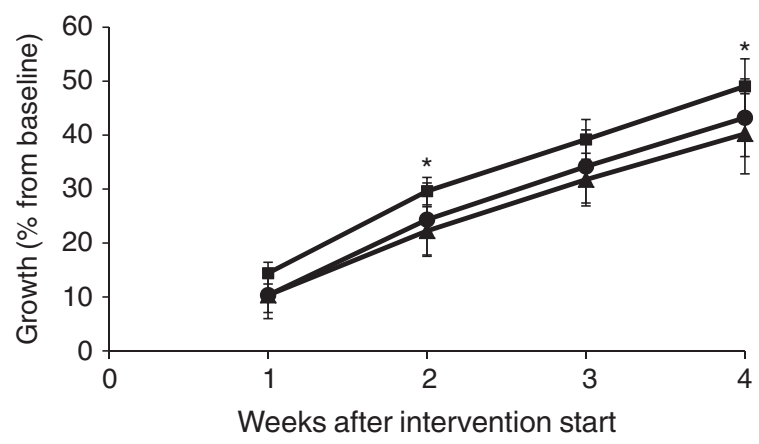

Fig. 1. Body weight gain during the intervention period, shown as percentage growth relative to baseline weight for rats fed casein/whey (CAS) ( $\mathbf{A})$, herring $(\bullet)$ or salmon ( $)$. * Mean value was significantly different from that of the CAS group $(P<0.05$; evaluated by one-way ANOVA with Dunnett's post hoc test).

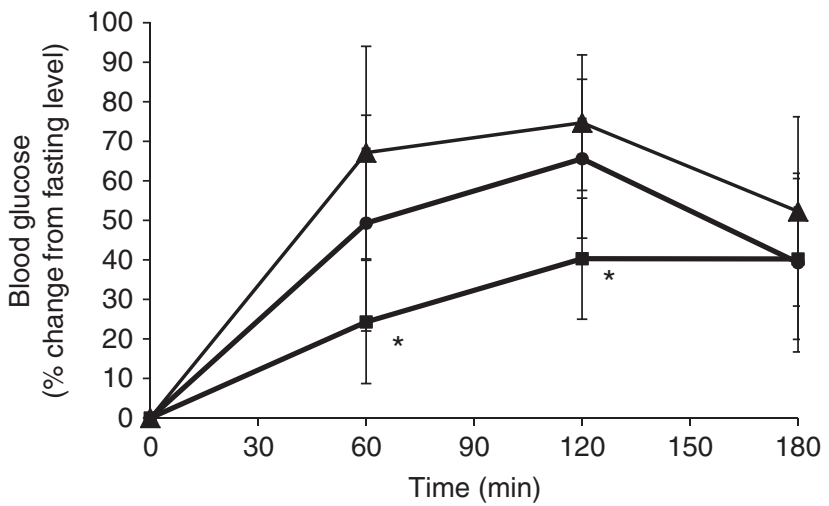

Fig. 2. Meal tolerance test, shown as percentage change from fasting levels in casein/whey (CAS) group $(\mathbf{A})$, herring group $(\bullet)$ and salmon group $(\boldsymbol{\square})$ in fasting state and after intake of a carbohydrate-rich meal. * Mean value was significantly different from that of the CAS group $(P<0.05$; evaluated by one-way ANOVA with Dunnett's post hoc test).

after intake of the carbohydrate-rich meal ( $2 \mathrm{~g}$ sucrose/kg body weight). The rise in glucose in SAL was significantly lower after 60 and $120 \mathrm{~min}$ ( $P$ values 0.023 and 0.012 , respectively) when compared with CAS, whereas the postprandial glucose response in the HER group was similar to CAS (Fig. 2). After $180 \mathrm{~min}$, no statistically significant differences were seen between fish hydrolysate groups and CAS.

\section{Biochemical analyses}

Serum concentrations of HDL-cholesterol and LDL-cholesterol were significantly lower, and the serum concentration of TAG was significantly higher in HER when compared with CAS ( $P$ values 0.026, 0.010 and 0.032, respectively, Table 4). Serum total cholesterol and cholesteryl ester levels tended to be lower in HER when compared with CAS $(P=0.093$ and 0.099, respectively). No differences were seen between SAL and CAS for serum cholesterols and TAG concentrations. No statistically significant differences were seen between CAS and fish hydrolysate groups regarding the mean concentrations of total bile acids, NEFA, insulin and alanine transaminase (Table 4). The TAG and total cholesterol contents in liver and thigh skeletal muscle and the faecal excretion of cholesterol, TAG and
Table 4. Circulating concentrations of lipids and enzymes (Mean values and standard deviations, $n 6$ rats in each group)

\begin{tabular}{|c|c|c|c|c|c|c|}
\hline & \multicolumn{2}{|c|}{ CAS } & \multicolumn{2}{|c|}{ HER } & \multicolumn{2}{|c|}{ SAL } \\
\hline & Mean & SD & Mean & SD & Mean & SD \\
\hline HDL-cholesterol (mmol/l) & 3.6 & 0.5 & $2 \cdot 9^{*}$ & 0.4 & 3.5 & 0.6 \\
\hline LDL-cholesterol (mmol/l') & 0.7 & 0.2 & $0.3^{*}$ & 0.1 & 0.6 & 0.3 \\
\hline Total cholesterol (mmol/l) & $4 \cdot 7$ & 0.7 & 3.9 & 0.4 & 4.4 & 0.8 \\
\hline Cholesteryl esters (mmol/l) & $3 \cdot 8$ & 0.5 & 3.2 & 0.3 & $3 \cdot 7$ & 0.7 \\
\hline Total bile acids (mmol/l) & $24 \cdot 2$ & $7 \cdot 8$ & $23 \cdot 8$ & $10 \cdot 4$ & $24 \cdot 2$ & $14 \cdot 5$ \\
\hline TAG $(\mathrm{mmol} / \mathrm{l})$ & $2 \cdot 7$ & 0.8 & $4 \cdot 3^{\star}$ & 1.6 & 3.0 & 0.5 \\
\hline NEFA (mmol/l) & 0.88 & 0.21 & 0.78 & 0.14 & 0.72 & 0.17 \\
\hline Insulin $(\mu \mathrm{g} / \mathrm{l})$ & 3.6 & 1.0 & 3.9 & 1.0 & $4 \cdot 3$ & $1 \cdot 3$ \\
\hline Alanine transaminase $(\mathrm{U} / \mathrm{I})$ & $60 \cdot 2$ & $4 \cdot 6$ & $51 \cdot 5$ & 11.6 & $62 \cdot 3$ & $13 \cdot 4$ \\
\hline
\end{tabular}

CAS, casein/whey; HER, herring; SAL, salmon.

* Mean value was significantly different from that of the CAS group $(P<0.05$; evaluated by one-way ANOVA with Dunnett's post hoc test).

total bile acids were not different between CAS and fish hydrolysate groups (data not presented).

\section{Fatty composition in serum, adipose tissue, liver and muscle}

Both fish hydrolysate diets affected the fatty acid composition in serum, but only the SAL diet affected WAT epididymal fatty acids (Table 5). Serum level of 16:0 was higher and that of $18: 0$ was lower in HER when compared with CAS, and none of the fish hydrolysate diets affected total SFA amount. The $\Delta-9$ desaturated MUFA 16:1n-7 and 18:1n-9 and the total concentration of MUFA in serum were higher in HER compared with the CAS group, whereas SAL seemed to not affect serum MUFA. HER and SAL rats had a significantly higher serum level of $18: 3 n-3$, and in addition HER rats had a higher serum level of $22: 5 n-3$; however, no difference was seen regarding serum total $n$-3 PUFA between CAS and fish hydrolysate groups. Serum level of $18: 2 n-6$ was higher in SAL rats and that of $20: 4 n-6$ was lower in both HER and SAL rats when compared with CAS. The total $n-6$ PUFA level was lower and the ratio of $n$-3:n-6 PUFA was higher in serum from HER rats when compared with the CAS group.

The HER diet did not affect the fatty acid composition in WAT relative to CAS. In WAT from SAL-fed rats, levels of 16:0 and total SFA were lower, and levels of $18: 3 n-3$ and total $n$ - 3 PUFA were higher when compared with CAS (Table 5). The fatty acid compositions in liver and muscle were not affected by any of the fish hydrolysate diets (data not presented).

\section{Discussion}

Fish intake is associated with improved blood lipid profile and glucose regulation, and could therefore prevent the development of type 2 diabetes and CVD in humans ${ }^{(51-55)}$. We have recently shown that when cod protein (as $25 \%$ of dietary protein) was fed to obese Zucker rats, serum concentrations of fasting NEFA and 2-h postprandial serum glucose were lower, and the ratios of $n-3: n-6$ PUFA in liver, epididymal WAT and serum were 
Table 5. Selected fatty acids in serum and epididymal white adipose tissue (Mean values and standard deviations, $n 6$ rats in each group)

\begin{tabular}{|c|c|c|c|c|c|c|}
\hline \multirow[b]{2}{*}{$\mathrm{g} / 100 \mathrm{~g}$ fatty acids } & \multicolumn{2}{|c|}{ CAS } & \multicolumn{2}{|c|}{ HER } & \multicolumn{2}{|c|}{ SAL } \\
\hline & Mean & SD & Mean & SD & Mean & SD \\
\hline \multicolumn{7}{|l|}{ Serum } \\
\hline $16: 0$ & $18 \cdot 7$ & 0.8 & $21 \cdot 1^{*}$ & 1.4 & $19 \cdot 1$ & 1.0 \\
\hline $18: 0$ & $13 \cdot 3$ & 0.8 & $11 \cdot 3^{*}$ & 1.6 & $12 \cdot 6$ & 0.6 \\
\hline$\Sigma$ SFA $†$ & 33.6 & 0.5 & 34.0 & 0.6 & 33.4 & 0.4 \\
\hline $16: 1 n-7$ & 3.77 & 0.46 & $4.5^{\star}$ & 0.57 & 4.01 & 0.43 \\
\hline $18: 1 n-9$ & $12 \cdot 0$ & 1.5 & $15 \cdot 6^{*}$ & $2 \cdot 2$ & $12 \cdot 9$ & 0.6 \\
\hline$\Sigma$ MUFA $\ddagger$ & $18 \cdot 7$ & $2 \cdot 2$ & $23 \cdot 2^{\star}$ & $2 \cdot 9$ & $20 \cdot 0$ & 0.8 \\
\hline $18: 3 n-3$ & 0.52 & 0.06 & $0.72^{\star}$ & 0.50 & $0.66^{*}$ & 0.05 \\
\hline $20: 5 n-3$ & 0.65 & 0.13 & 0.74 & $0 \cdot 17$ & 0.78 & 0.08 \\
\hline $22: 5 n-3$ & 0.88 & 0.07 & $1.05^{\star}$ & $0 \cdot 12$ & 0.90 & 0.08 \\
\hline $22: 6 n-3$ & 3.75 & 0.34 & 3.79 & 0.34 & 3.80 & 0.35 \\
\hline$\Sigma n-3$ PUFA§ & 5.79 & 0.38 & $6 \cdot 21$ & 0.31 & $6 \cdot 15$ & 0.42 \\
\hline $18: 2 n-6$ & $10 \cdot 0$ & 1.0 & 10.9 & 1.0 & $11 \cdot 7^{\star}$ & 0.7 \\
\hline $20: 4 n-6$ & 29.5 & $2 \cdot 4$ & $23 \cdot 2^{*}$ & $3 \cdot 7$ & $26 \cdot 6^{\star}$ & 1.4 \\
\hline$\Sigma n-6$ PUFAll & 41.9 & $2 \cdot 1$ & $36 \cdot 6^{*}$ & $2 \cdot 8$ & $40 \cdot 4$ & 1.1 \\
\hline$\Sigma n-3: \Sigma n-6$ PUFA & 0.139 & 0.009 & $0.171^{*}$ & 0.020 & 0.152 & 0.012 \\
\hline \multicolumn{7}{|l|}{ White adipose tissue } \\
\hline $16: 0$ & $30 \cdot 1$ & 0.6 & $30 \cdot 1$ & 0.6 & $29 \cdot 3^{*}$ & 0.4 \\
\hline $18: 0$ & 4.87 & 0.32 & 4.54 & 0.58 & 4.09 & 0.93 \\
\hline$\Sigma$ SFA $†$ & 37.0 & 0.8 & $36 \cdot 6$ & 0.7 & $35 \cdot 4^{*}$ & 1.0 \\
\hline $16: 1 n-7$ & 7.57 & 0.47 & 7.84 & 0.54 & 8.29 & 1.57 \\
\hline $18: 1 n-9$ & 32.5 & 0.7 & $32 \cdot 1$ & 1.3 & $31 \cdot 3$ & 1.4 \\
\hline$\Sigma$ MUFA $\ddagger$ & 44.2 & 0.8 & $44 \cdot 0$ & 1.3 & 43.7 & 1.9 \\
\hline $18: 3 n-3$ & 1.62 & 0.15 & 1.68 & 0.08 & $1.83^{*}$ & 0.16 \\
\hline $20: 5 n-3$ & 0.027 & 0.003 & 0.028 & 0.003 & 0.030 & 0.004 \\
\hline $22: 5 n-3$ & 0.11 & 0.01 & $0 \cdot 11$ & 0.02 & 0.12 & 0.02 \\
\hline $22: 6 n-3$ & 0.13 & 0.02 & $0 \cdot 15$ & 0.02 & $0 \cdot 16$ & 0.03 \\
\hline$\Sigma n-3$ PUFA§ & 1.9 & 0.2 & 2.0 & $0 \cdot 1$ & $2 \cdot 2^{*}$ & 0.2 \\
\hline $18: 2 n-6$ & $16 \cdot 1$ & $1 \cdot 3$ & $16 \cdot 7$ & 1.0 & $17 \cdot 9$ & $1 \cdot 6$ \\
\hline $20: 4 n-6$ & 0.38 & 0.03 & 0.41 & 0.05 & 0.44 & 0.04 \\
\hline$\Sigma n-6$ PUFAll & $16 \cdot 9$ & 1.3 & 17.4 & 1.1 & $18 \cdot 7$ & 1.6 \\
\hline$\Sigma n-3: \Sigma n-6$ PUFA & 0.114 & 0.004 & 0.114 & 0.003 & 0.116 & 0.003 \\
\hline
\end{tabular}

CAS, casein/whey; HER, herring; SAL, salmon.

* Mean value was significantly different from that of the CAS group $(P<0.05$; evaluated by one-way ANOVA with Dunnett's post hoc test)

t Sum of $12: 0,14: 0,15: 0,16: 0,17: 0,18: 0,20: 0,22: 0,23: 0,24: 0$.

$\ddagger$ Sum of $14: 1 n-5,16: 1 n-7,16: 1 n-9,17: 1 n-8,18: 1 n-5,18: 1 n-7,18: 1 n-9,20: 1 n-9,24: 1 n-9$.

$\S$ Sum of $18: 3 n-3,20: 3 n-3,20: 5 n-3,22: 5 n-3,22: 6 n-3$.

II Sum of $18: 2 n-6,18: 3 n-6,20: 3 n-6,20: 4 n-6,22: 4 n-6,22: 5 n-6$.

higher when compared with a casein-fed control group ${ }^{(21)}$. In the present study, we wanted to investigate the effects of herring and salmon protein hydrolysates on lipid metabolism and glucose regulation when obese Zucker fa/fa rats were fed diets in which fish hydrolysates constituted $25 \%$ of dietary protein. The amount of peptides with a molecular weight of $200-1000 \mathrm{~g} / \mathrm{mol}$ (comprising peptides with approximately $2-5$ amino acids) were similar in the two fish protein hydrolysates, and none of the diets contained measurable amounts of long-chain $n-3$ PUFA. Both herring and salmon hydrolysates tested in the present study contained motifs with reported hypocholesterolemic and/or antidiabetic effects ${ }^{(35-48)}$. To our knowledge, this is the first study testing dietary hydrolysed fish protein with identified bioactive motifs with hypocholesterolemic and antidiabetic activities in obese rats.

Motifs with antidiabetic properties have been identified in various species of fish: VW is found in sardine muscle ${ }^{(47)}$ and skin and residual material from Atlantic herring ${ }^{(26)}$; YYPL is found in sardine muscle ${ }^{(47)}$; GPAE and GPGA are found in Atlantic salmon skin ${ }^{(36)}$; and GPL is found in skin and residual material from Alaska pollock, Atlantic herring, Atlantic salmon and Atlantic cod ${ }^{(26,27,56)}$. In addition, hypocholesterolemic motifs have been found in fish: HIRL and IIAEK have been found in residual material from herring ${ }^{(26)}$. When searching for known motifs with hypocholesterolemic and/or antidiabetic effects $^{(35-48)}$ in our herring and salmon hydrolysates, we found the antidiabetic motifs IPI, GPL and VW and the combined antidiabetic and hypocholesterolemic PGPL in both hydrolysates. In addition, we found the hypocholesterolemic motif IIAEK and the antidiabetic motifs GPAE and LPGP only in herring.

The weights of liver, thigh muscle and epididymal WAT relative to body weight and the serum alanine transaminase concentration were not different between CAS and the fish hydrolysate groups, and thus we conclude that there are no indications of serious organ damage in any of the intervention groups. The energy intake was similar between the CAS and the fish hydrolysate groups; however, as the growth was significantly higher in SAL rats compared with CAS, this suggests a better utilisation of the feed in the SAL group. This is in contrast to findings in which 
Wistar rats fed a high-fat, high-sucrose diet with salmon hydrolysates as the sole protein source had a lower weight gain compared with similar diets with casein or herring hydrolysates despite similar energy intakes in all groups ${ }^{(17)}$; however, this latter study uses a different rat strain and a high-energy diet, and no information on the peptide size distribution was given.

We have previously shown that a daily intake $6 \mathrm{~g}$ of cod protein as supplement was sufficient to affect postprandial glucose and insulin concentrations in overweight subjects ${ }^{(12)}$, and recently we also found that cod protein feeding reduced 2-h postprandial glucose in obese Zucker fa/fa rats without affecting fasting serum concentrations of glucose and insulin ${ }^{(21)}$. In the present study, no differences were seen in fasting glucose concentration between the HER and SAL groups and controls before the start of the meal tolerance test, indicating that the fish hydrolysates did not influence fasting glucose regulation. The mean increase in glucose was significantly smaller after 60 and $120 \mathrm{~min}$ in the SAL group when compared with CAS, strongly indicating a better postprandial glucose regulation in SAL, whereas HER did not seem to affect postprandial glucose regulation when compared with CAS. Postprandial regulation of glucose may be of more interest than solely looking at fasting concentrations of glucose when interpreting these findings in relation to humans, as we spend most of our time in a postprandial state. Findings in animal and clinical studies suggest that cod protein improves glucose regulation ${ }^{(12,16,17,19,21)}$, but there is controversy as to the glucose-regulating effects of fatty fish or fish oil ${ }^{(4-6,17,57-59)}$. As both HER and SAL diets, and not CAS diet, contained taurine, it is of interest that taurine has been shown to have hypoglycaemic effect in rats, by increasing the glucose uptake without increasing insulin secretion ${ }^{(60)}$. Unfortunately, insulin was not measured during the meal tolerance test, but fasting insulin in serum from time of euthanasia was not different between CAS and fish hydrolysate groups. In line with this, no differences were seen in serum concentration of NEFA, which is regarded as a risk factor for the development of insulin resistance in humans ${ }^{(61)}$, between CAS and fish hydrolysate groups. A possible explanation for the observed improvement of postprandial glucose regulation in SAL is that the salmon hydrolysate contained the antidiabetic motifs IPI, GPL, PGPL and $\mathrm{VW}^{(37,41-43,47)}$. Of these motifs, IPI and PGPL may be of special interest in the current setting. IPI is the most potent dipeptidyl peptidase-IV (DPP-IV) inhibitor found to date ${ }^{(62)}$ and therefore holds potential as a possible approach for management of type 2 diabetes, and PGPL seem to protect against alloxan-induced IDDM in rats by preventing blood sugar increase ${ }^{(42)}$

The impact of salmon hydrolysates on cholesterol metabolism has been investigated in a range of rodent models with various results. We have previously shown that when hydrolysed salmon protein was the sole dietary protein source, the plasma concentrations of total cholesterol and HDL-cholesterol were lower in Zucker fa/fa rats but unaffected in Wistar rats when compared with rats fed a casein-based diet ${ }^{(14)}$. In the present study, SAL did not affect serum cholesterol concentrations, whereas HER-fed rats had lower serum concentrations of HDL-cholesterol and LDL-cholesterol and tended to have lower serum total cholesterol and cholesteryl ester concentrations. It has been suggested that fish protein has a cholesterol-lowering effect because of lower ratios of methionine:glycine and of lysine:arginine ${ }^{(14,63,64)}$. In the present study, the methionine: glycine and lysine:arginine ratios were lower in both HER and SAL diets when compared with CAS, despite no effect of SAL on serum cholesterol concentrations. In addition, dietary taurine has been shown to reduce serum cholesterol in rats by increasing the conversion of cholesterol to bile acids for faecal excretion $^{(65)}$. Rats are able to conjugate cholic acid with both glycine and taurine, but prefer taurine ${ }^{(66)}$, and of the diets tested in the present study the highest taurine content was found in the HER diet, and glycine content in fish hydrolysate diets was approximately twice that of CAS. Of particular interest is that the hypocholesterolemic motif IIAEK was identified in the herring hydrolysate, as we have also shown previously ${ }^{(26)}$. IIAEK has been shown to have greater cholesterol-lowering capacity than $\beta$-sitosterol (on a weight-to-weight basis) in rats ${ }^{(35)}$, and the proposed mechanism for the hypocholesterolemic effect of IIAEK is through increased cholesterol $7 \alpha$-hydroxylase gene expression $^{(67)}$. Faecal excretion of neutral and acidic steroids is the major route of cholesterol removal from the body, but despite the lowering effects of HER on serum cholesterols and the relatively high taurine intake the faecal content of bile acids and cholesterol, as well as the serum bile acid concentration, did not seem to be affected by the diet. Adding to this, no differences were seen between cholesterol contents in liver and muscle for HER- and CAS-fed rats.

The serum TAG concentration was not affected by the SAL diet, but was significantly higher in HER rats when compared with the CAS group. The effects of hydrolysed salmon and herring proteins on circulating TAG in obese Zucker rats have not been reported before, but we and others have shown that salmon hydrolysates ${ }^{(14,17,68)}$ and herring hydrolysates ${ }^{(17)}$ did not affect plasma TAG concentration in Wistar rats. We have previously reported higher circulating concentration of TAG concomitantly with lower cholesterol levels in obese Zucker $\mathrm{fa} / \mathrm{fa}$ rats fed normal-energy diets supplemented with fermented single-cell proteins with low lysine:arginine ratio compared with casein ${ }^{(69,70)}$ or soya proteins with high content of isoflavones $^{(69,71)}$, whereas others have shown that diets with low ratios of lysine:arginine reduced serum TAG concentration in Wistar rats ${ }^{(72)}$. The obese Zucker rats have an abnormal lipid metabolism and are hyperlipidaemic ${ }^{(28)}$, and TAG-rich lipoproteins from obese Zucker rats fed casein contain approximately $80 \% \mathrm{TAG}^{(71)}$. Therefore, the high serum TAG concentration in HER-fed rats is possibly because of higher level of TAG-rich lipoproteins such as VLDL, whereas the serum concentration of cholesterol-richer LDL and HDL are probably lower in HER rats.

The fatty acid compositions of the three experimental diets were identical, and no traces of long-chain $n$-3 PUFA were found in any of the diets. It was therefore of interest that both fish hydrolysate diets seem to affect fatty acid composition in serum. The most pronounced differences were seen in serum from HER-fed rats, with higher $n-3: n-6$ PUFA ratio because of the higher levels of $18: 3 n-3$ and $22: 5 n-3$, and lower level of 20:4n-6 when compared with CAS, but we did not see the same trend in liver, skeletal muscle and WAT. As we found only 
marginal differences in the longer $n-3$ PUFA in serum between the HER group and CAS, it is not likely that HER affected the desaturation and elongation of $18: 3 n-3$ to the long-chain $n$ - 3 PUFA. This is supported by the findings that HER did not affect the fatty acid composition in liver, which is a quantitative important site for desaturation and elongation of PUFA. On the other hand, the concentrations of the $\Delta-9$ desaturated MUFA $16: 1 n-7$ and $18: 1 n-9$ were significantly higher in HER rats (but not in SAL rats) when compared with CAS, suggesting an up-regulation of $\Delta-9$ desaturase activity. However, no differences were seen in amounts of $\Delta-9$ desaturated MUFA in liver, the main site of $\Delta-9$ desaturation, in HER and SAL groups. We have previously seen higher circulating levels of $\Delta-9$ desaturated MUFA after feeding Zucker fa/fa rats hydrolysed salmon proteins (as $100 \%$ of protein source); but this seems not to be due to transcriptional up-regulation of stearoyl-CoA desaturase, as the hepatic stearoyl-CoA desaturase mRNA level was unaffected $^{(14)}$.

In epididymal WAT, the HER diet did not affect the fatty acid composition, but the SAL-fed rats had lower total SFA and higher total n-3 PUFA concentrations when compared with CAS, which may be regarded as beneficial effects of the SAL diet. The findings regarding fatty acids after herring or salmon hydrolysate intake in the present study differs greatly from our recent paper on cod protein diet $(25 \%$ of dietary protein as cod protein) in obese Zucker rats where we saw a higher n-3:n-6 PUFA ratio in serum, liver and WAT, possibly due to up-regulation of desaturase and elongase activities caused by increased postprandial insulin secretion $^{(21)}$

To conclude, our findings show that when obese Zucker fa/fa rats were fed a diet containing herring protein hydrolysate (HER, 25\% of protein intake), this resulted in lower serum concentrations of HDL-cholesterol and LDL-cholesterol, possibly because of a high dietary content of taurine, low ratios of lysine:arginine and methionine:glycine and/or the presence of the hypocholesterolemic motif IIAEK, when compared with the CAS diet. In addition, the serum TAG and MUFA concentrations, as well as the n-3:n-6 PUFA ratio, were higher in HER rats when compared with CAS. On the other hand, when obese Zucker $\mathrm{fa} / \mathrm{fa}$ rats were fed a diet containing salmon protein hydrolysate (SAL, $25 \%$ of protein intake), the growth was greater and the postprandial glucose regulation was improved when compared with CAS, the latter possibly due to the presence of antidiabetic motifs in the salmon hydrolysate. However, although several beneficial motifs with known hypocholesterolemic and/or antidiabetic activity were identified in the herring and salmon hydrolysates, we have no information about whether these motifs exist as bioactive peptides that can be absorbed from the intestine as such, or as inactive sequences in a longer amino acid sequence. In addition, SAL rats had lower total SFA and higher total $n$-3 PUFA concentrations in adipose tissue when compared with CAS, but the serum fatty acid composition was only marginally affected and no effects were observed in serum lipid concentrations. In vitro enzymatic hydrolysis of proteins to small peptides results in bioactive peptides that can be absorbed directly from the intestine, and future studies should investigate the effects of fish protein hydrolysates and selected bioactive peptides identified in fish protein hydrolysates in human populations with metabolic disturbances such as obesity, type 2 diabetes and/or hypercholesterolaemia.

\section{Acknowledgements}

K.B. Øysæd and E. Larssen (IRIS) are acknowledged for their technical support in the bioactive motif identification in fish protein hydrolysates.

The present research has been supported by funding from the Bergen Medical Research Foundation and the Regional research fund of Western Norway (project no. 212625). These sponsors were not involved in the design of the study, data collection, analysis and interpretation of data, writing of the article or in the decision to submit the article for publication.

T. R., I. H. and O. A. G. formulated the research question and designed the study. R. S., A. C., T. R. and I. H. prepared the fish protein hydrolysates for the study. A. D. and O. A. G. conducted the animal study. A. D., S. A. M., D. M. P. and O. A. G. analysed the data and performed statistical analyses. O. A. G. drafted the paper and had primary responsibility for the final content. All authors have contributed to the writing and approved the final manuscript.

T. R. is employed in Nutrimar AS, which is owned by the investment company Kverva AS who also own SalMar ASA. SalMar ASA is one of the world's largest producers of farmed salmon, and provided fresh salmon backbones for this study. I. H. is CEO and Chairman of Blue Protein, a company that commercialises new products based on fish proteins from fish by-products. Nutrimar AS, Kverva AS, SalMar ASA and Blue Protein were not involved in on-site data collection. The other authors declare no conflicts of interest.

\section{References}

1. Harris WS (1989) Fish oils and plasma lipid and lipoprotein metabolism in humans: a critical review. J Lipid Res 30, $785-807$.

2. Harris WS (1997) $n-3$ Fatty acids and serum lipoproteins: human studies. Am J Clin Nutr 65, 1645S-1654S.

3. Smith KM, Barraj LM, Kantor M, et al. (2009) Relationship between fish intake, $n-3$ fatty acids, mercury and risk markers of CHD (National Health and Nutrition Examination Survey 1999-2002). Public Health Nutr 12, 1261-1269.

4. Kromhout D \& de Goede J (2014) Update on cardiometabolic health effects of omega-3 fatty acids. Curr Opin Lipidol 25 , 85-90.

5. Glauber H, Wallace P, Griver K, et al. (1988) Adverse metabolic effect of omega-3 fatty acids in non-insulin-dependent diabetes mellitus. Ann Intern Med 108, 663-668.

6. Popp-Snijders C, Schouten JA, Heine RJ, et al. (1987) Dietary supplementation of omega-3 polyunsaturated fatty acids improves insulin sensitivity in non-insulin-dependent diabetes. Diabetes Res $\mathbf{4}, 141-147$.

7. Eslick GD, Howe PR, Smith C, et al. (2009) Benefits of fish oil supplementation in hyperlipidemia: a systematic review and meta-analysis. Int J Cardiol 136, 4-16.

8. Nettleton JA \& Katz R (2005) n-3 Long-chain polyunsaturated fatty acids in type 2 diabetes: a review. J Am Diet Assoc $\mathbf{1 0 5}$, 428-440. 
9. Balk EM, Lichtenstein AH, Chung M, et al. (2006) Effects of omega-3 fatty acids on serum markers of cardiovascular disease risk: a systematic review. Atherosclerosis 189, 19-30.

10. Jacques H (1990) Effects of dietary fish protein on plasma cholesterol and lipoproteins in animal models and in humans. Monogr Atheroscler 16, 59-70.

11. Thorsdottir I, Tomasson H, Gunnarsdottir I, et al. (2007) Randomized trial of weight-loss-diets for young adults varying in fish and fish oil content. Int J Obes (Lond) 31, 1560-1566.

12. Vikoren LA, Nygard OK, Lied E, et al. (2013) A randomised study on the effects of fish protein supplement on glucose tolerance, lipids and body composition in overweight adults. Br J Nutr 109, 648-657.

13. Ouellet V, Marois J, Weisnagel SJ, et al. (2007) Dietary cod protein improves insulin sensitivity in insulin-resistant men and women: a randomized controlled trial. Diabetes Care $\mathbf{3 0}$, 2816-2821.

14. Wergedahl H, Liaset B, Gudbrandsen OA, et al. (2004) Fish protein hydrolysate reduces plasma total cholesterol, increases the proportion of HDL cholesterol, and lowers Acyl-CoA: cholesterol acyltransferase activity in liver of Zucker rats.

J Nutr 134, 1320-1327.

15. Hosomi R, Fukunaga $\mathrm{K}$, Arai $\mathrm{H}$, et al. (2011) Fish protein decreases serum cholesterol in rats by inhibition of cholesterol and bile acid absorption. J Food Sci 76, H116-H121.

16. Lavigne C, Marette A \& Jacques H (2000) Cod and soy proteins compared with casein improve glucose tolerance and insulin sensitivity in rats. Am J Physiol Endocrinol Metab 278, E491-E500.

17. Pilon G, Ruzzin J, Rioux LE, et al. (2011) Differential effects of various fish proteins in altering body weight, adiposity, inflammatory status, and insulin sensitivity in high-fat-fed rats. Metabolism 60, 1122-1130.

18. Madani Z, Louchami K, Sener A, et al. (2012) Dietary sardine protein lowers insulin resistance, leptin and TNF-alpha and beneficially affects adipose tissue oxidative stress in rats with fructose-induced metabolic syndrome. Int J Mol Med 29, 311-318.

19. Lavigne C, Tremblay F, Asselin G, et al. (2001) Prevention of skeletal muscle insulin resistance by dietary cod protein in high fat-fed rats. Am J Physiol Endocrinol Metab 281, E62-E71.

20. Shukla A, Bettzieche A, Hirche F, et al. (2006) Dietary fish protein alters blood lipid concentrations and hepatic genes involved in cholesterol homeostasis in the rat model. Br J Nutr 96, 674-682.

21. Drotningsvik A, Mjos SA, Hogoy I, et al. (2015) A low dietary intake of cod protein is sufficient to increase growth, improve serum and tissue fatty acid compositions, and lower serum postprandial glucose and fasting non-esterified fatty acid concentrations in obese Zucker fa/fa rats. Eur J Nutr $\mathbf{5 4}$, 1151-1160.

22. Hagen IV, Helland A, Bratlie M, et al. (2016) High intake of fatty fish, but not of lean fish, affects serum concentrations of TAG and HDL-cholesterol in healthy, normal-weight adults: a randomised trial. BrJ Nutr 116, 648-657.

23. FAO Fisheries Department (2014) The State of World Fisheries and Aquaculture. Rome: FAO

24. Ryan JT, Ross RP, Bolton D, et al. (2011) Bioactive peptides from muscle sources: meat and fish. Nutrients $\mathbf{3}$, 765-791.

25. Kim SK \& Wijesekara I (2010) Development and biological activities of marine-derived bioactive peptides: a review. J Funct Foods 2, 1-9.
26. Pampanin DM, Larssen E, Provan F, et al. (2012) Detection of small bioactive peptides from Atlantic herring (Clupea harengus L.). Peptides 34, 423-426.

27. Pampanin DM, Haarr MB \& Sydnes MO (2016) Natural peptides with antioxidant activity from Atlantic cod and Atlantic salmon residual materia. Int J Appl Res Nat Prod 9, $1-8$.

28. de Artinano AA \& Castro MM (2009) Experimental rat models to study the metabolic syndrome. Br J Nutr $\mathbf{1 0 2}$, 1246-1253.

29. Reeves PG, Nielsen FH \& Fahey GC Jr (1993) AIN-93 purified diets for laboratory rodents: final report of the American Institute of Nutrition ad boc writing committee on the reformulation of the AIN-76A rodent diet. J Nutr $\mathbf{1 2 3}$, 1939-1951

30. Oterhals A \& Samuelsen TA (2015) Plasticization effect of solubles in fishmeal. Food Res Int 69, 313-321.

31. Bligh EG \& Dyer WJ (1959) A rapid method of total lipid extraction and purification. Can J Biochem Physiol 37, 911-917.

32. Meier S, Mjos SA, Joensen H, et al. (2006) Validation of a onestep extraction/methylation method for determination of fatty acids and cholesterol in marine tissues. J Chromatogr $A \mathbf{1 1 0 4}$, 291-298.

33. Sciotto C \& Mjos SA (2012) Trans isomers of EPA and DHA in omega-3 products on the European market. Lipids $\mathbf{4 7}$, 659-667.

34. Wasta Z \& Mjos SA (2013) A database of chromatographic properties and mass spectra of fatty acid methyl esters from omega-3 products. J Chromatogr A 1299, 94-102.

35. Nagaoka S, Futamura Y, Miwa K, et al. (2001) Identification of novel hypocholesterolemic peptides derived from bovine milk beta-lactoglobulin. Biochem Biophys Res Commun 281, 11-17.

36. Li-Chan EC, Hunag SL, Jao CL, et al. (2012) Peptides derived from Atlantic salmon skin gelatin as dipeptidyl-peptidase IV inhibitors. J Agric Food Chem 60, 973-978.

37. Ben Henda Y, Laamari M, Lanneluc I, et al. (2015) Di and tripeptides from marine sources can target adipogenic process and contribute to decrease adipocyte number and functions. J Funct Foods 17, 1-10.

38. Yamauchi R, Ohinata K \& Yoshikawa M (2003) Beta-lactotensin and neurotensin rapidly reduce serum cholesterol via NT2 receptor. Peptides 24, 1955-1961.

39. Yoshikawa M, Fujita H, Matoba N, et al. (2000) Bioactive peptides derived from food proteins preventing lifestylerelated diseases. Biofactors 12, 143-146.

40. Lammi C, Zanoni C \& Arnoldi A (2015) IAVPGEVA, IAVPTGVA, and LPYP, three peptides from soy glycinin, modulate cholesterol metabolism in HepG2 cells through the activation of the LDLR-SREBP2 pathway. J Funct Foods 14 , 469-478.

41. Umezawa H, Aoyagi T, Ogawa K, et al. (1984) Diprotins $\mathrm{A}$ and $\mathrm{B}$, inhibitors of dipeptidyl aminopeptidase IV, produced by bacteria. J Antibiot (Tokyo) 37, 422-425.

42. Lyapina LA, Myasoedov NF, Grigorjeva ME, et al. (2013) The modern concept of the regulatory role of peptides of the glyproline family in the correction of hemostasis system function during development of diabetes mellitus. Biol Bull 40, 386-393.

43. Myasoedov NF, Lyapina LA, Grigorjeva ME, et al. (2016) Mechanisms for glyproline protection in hypercholesterolemia. Pathophysiology 23, 27-33.

44. Yoshikawa M (2015) Bioactive peptides derived from natural proteins with respect to diversity of their receptors and physiological effects. Peptides 72, 208-225. 
45. Takenaka Y, Nakamura F, Yamamoto T, et al. (2003) Enterostatin (VPDPR) and its peptide fragment DPR reduce serum cholesterol levels after oral administration in mice. Biosci Biotechnol Biochem 67, 1620-1622.

46. Kagawa K, Matsutaka H, Fukuhama C, et al. (1996) Globin digest, acidic protease hydrolysate, inhibits dietary hypertriglyceridemia and Val-Val-Tyr-Pro, one of its constituents, possesses most superior effect. Life Sci 58, 1745-1755.

47. Matsui T, Oki T \& Osajima Y (1999) Isolation and identification of peptidic alpha-glucosidase inhibitors derived from sardine muscle hydrolyzate. $Z$ Naturforsch C 54, 259-263.

48. Yamada Y, Muraki A, Oie M, et al. (2012) Soymorphin-5, a soy-derived mu-opioid peptide, decreases glucose and triglyceride levels through activating adiponectin and PPARalpha systems in diabetic KKAy mice. Am J Physiol Endocrinol Metab 302, E433-E440.

49. Suckling KE, Benson GM, Bond B, et al. (1991) Cholesterol lowering and bile acid excretion in the hamster with cholestyramine treatment. Atherosclerosis 89, 183-190.

50. Farris EJ \& Griffith JQ (1949) The Rat in Laboratory Investigation. Philadelphia, PA: J. B. Lippincott Company.

51. Feskens EJ, Bowles CH \& Kromhout D (1991) Inverse association between fish intake and risk of glucose intolerance in normoglycemic elderly men and women. Diabetes Care 14, 935-941.

52. Whelton SP, He J, Whelton PK, et al. (2004) Meta-analysis of observational studies on fish intake and coronary heart disease. Am J Cardiol 93, 1119-1123.

53. Patel PS, Forouhi NG, Kuijsten A, et al. (2012) The prospective association between total and type of fish intake and type 2 diabetes in 8 European countries: EPIC-InterAct Study. Am J Clin Nutr 95, 1445-1453.

54. Nkondjock A \& Receveur O (2003) Fish-seafood consumption, obesity, and risk of type 2 diabetes: an ecological study. Diabetes Metab 29, 635-642.

55. Kromhout D, Bosschieter EB \& de Lezenne Coulander C (1985) The inverse relation between fish consumption and 20-year mortality from coronary heart disease. $N$ Engl J Med 312, 1205-1209.

56. Byun HG \& Kim SK (2002) Structure and activity of angiotensin I converting enzyme inhibitory peptides derived from Alaskan pollack skin. J Biochem Mol Biol 35, 239-243.

57. Bhathena SJ, Berlin E, Judd JT, et al. (1991) Effects of omega 3 fatty acids and vitamin $\mathrm{E}$ on hormones involved in carbohydrate and lipid metabolism in men. Am J Clin Nutr $\mathbf{5 4}$, 684-688.

58. Mori TA, Bao DQ, Burke V, et al. (1999) Dietary fish as a major component of a weight-loss diet: effect on serum lipids, glucose, and insulin metabolism in overweight hypertensive subjects. Am J Clin Nutr 70, 817-825.
59. Lara JJ, Economou M, Wallace AM, et al. (2007) Benefits of salmon eating on traditional and novel vascular risk factors in young, non-obese healthy subjects. Atherosclerosis 193, 213-221.

60. Kulakowski EC \& Maturo J (1984) Hypoglycemic properties of taurine: not mediated by enhanced insulin release. Biochem Pharmacol 33, 2835-2838.

61. Roden M, Price TB, Perseghin G, et al. (1996) Mechanism of free fatty acid-induced insulin resistance in humans. $J$ Clin Invest 97, 2859-2865.

62. Jao CL, Hung CC, Tung YS, et al. (2015) The development of bioactive peptides from dietary proteins as a dipeptidyl peptidase IV inhibitor for the management of type 2 diabetes. Biomedicine (Taipei) 5, 14.

63. Kritchevsky D, Tepper SA, Czarnecki SK, et al. (1982) Atherogenicity of animal and vegetable protein. Influence of the lysine to arginine ratio. Atherosclerosis 41, 429-431.

64. Morita T, Oh-hashi A, Takei K, et al. (1997) Cholesterollowering effects of soybean, potato and rice proteins depend on their low methionine contents in rats fed a cholesterol-free purified diet. J Nutr 127, 470-477.

65. Murakami S, Nara Y \& Yamori Y (1996) Taurine accelerates the regression of hypercholesterolemia in stroke-prone spontaneously hypertensive rats. Life Sci 58, 1643-1651.

66. Bremer J (1955) The conjugation of glycine with cholic acid and benzoic acid in rat liver homogenate. Acta Chem Scand $\mathbf{9}$, 268-271.

67. Morikawa K, Kondo I, Kanamaru Y, et al. (2007) A novel regulatory pathway for cholesterol degradation via lactostatin. Biochem Biophys Res Commun 352, 697-702.

68. Wergedahl H, Gudbrandsen OA, Rost TH, et al. (2009) Combination of fish oil and fish protein hydrolysate reduces the plasma cholesterol level with a concurrent increase in hepatic cholesterol level in high-fat-fed Wistar rats. Nutrition 25, 98-104.

69. Gudbrandsen OA, Wergedahl H, Liaset B, et al. (2005) Dietary proteins with high isoflavone content or low methionineglycine and lysine-arginine ratios are hypocholesterolaemic and lower the plasma homocysteine level in male Zucker $\mathrm{fa} / \mathrm{fa}$ rats. Br J Nutr $\mathbf{9 4}, 321-330$.

70. Gudbrandsen OA, Wergedahl H, Liaset B, et al. (2008) Dietary single cell protein reduces fatty liver in obese Zucker rats. Br J Nutr 100, 776-785.

71. Gudbrandsen OA, Wergedahl H, Mork S, et al. (2006) Dietary soya protein concentrate enriched with isoflavones reduced fatty liver, increased hepatic fatty acid oxidation and decreased the hepatic mRNA level of VLDL receptor in obese Zucker rats. Br J Nutr 96, 249-257.

72. Sugano M, Ishiwaki N, Nagata Y, et al. (1982) Effects of arginine and lysine addition to casein and soya-bean protein on serum lipids, apolipoproteins, insulin and glucagon in rats. Br J Nutr 48, 211-221. 